\title{
Junk Food Consumption and its Associated Factors in High School Students in Rasht in 2017
}

\section{Leila Mirhadyan ${ }^{1}$, Saeid Moradi Latreyi ${ }^{* *}$, AfsanehPasha ${ }^{1}$, Ehsan Kazem Nejad Leili}

1. School of Nursing and Midwifery, Guilan University of Medical Sciences, Rasht, Iran.

2. Social Determinants of Health Research Center, Guilan University of Medical Sciences, Rasht, Iran.

*Correspondence: School of Nursing and Midwifery, Guilan University of Medical Sciences, Rasht, Iran..Tel: +98-9114652855. E-mail: saeid.300371@gmail.com

Received July 12, 2018; Accepted December 25, 2019

\section{Abstract}

Background: Junk food consumption is an unhealthy adolescent nutritional habit that is affected by family structure, peer groups, and socioeconomic status. The present study was conducted to determine the association between junk food consumption and personal, familial, and social characteristics considering high school students in Rasht, Iran.

Methods: This cross-sectional study was conducted on 341 students in their second year of high school in Rasht, Iran in 2017. They were selected using a two-stage cluster random sampling. Data was collected using a checklist. Data was analyzed in SPSS 16 using Mann-Whitney and Kruskal-Wallis tests at a significance level of 0.05 .

Results: Sweet snacks were consumed the most (27.3\%). Frequency of junk food consumption was significantly higher in students whose fathers had a university degree $(\mathrm{P}=0.037)$ and those with monthly family income of more than 2 million Rials. $(\mathrm{P}=0.004)$.

Conclusions: The results indicate that students whose fathers have a higher education and income level have more tendencies toward junk food consumption; hence, it is worth considering the relevant factors in order to improve the adolescents' health.

Keywords: Adolescent; Nutrition; Snacks; Family; Fast food

\subsection{2/jgbfnm.17.1.52}




\section{Introduction}

The "junk food" term was introduced by Michael Jacobson in 1972 and it covered the salty and sweet snacks, fried fast food, and sweet carbonated drinks. Furthermore, burgers, pizzas, and sandwiches can be put in this category based on their ingredients and preparation methods $(1,2)$. These foods which have high calories, salt or sugar, while low vitamins, minerals, and fiber increase the incidence of diseases such as obesity, diabetes, cardiovascular diseases, and hypertension in adulthood (2 -4).

As adolescents reach puberty, significant changes are made in their appearance, mood, social behavior, and mental state (5) that exposes them to high-risk health behaviors including inappropriate nutritional habits $(6,7)$. Refusing to eat breakfast, low consumption of fruits, high consumption of fast food and non-nutritious snakes, low quality and quantity of meals, eating outdoors and variable dietary patterns are common habits that cause problems such as obesity in adolescents (8).

According to studies, the causes of dramatic increase in consumption of junk food in adolescents are the taste change, quick and easy access, being delicious, family structure, low cost, and tendency to these foods (9). Other studies have mentioned the roles of factors such as family and peers in the acquisition of nutrition knowledge and in taking measure to conduct a nutritional behavior $(8,10,11)$. Family is the first founder of character, and intellectual values and standards of children. Psychologists believe that parents significantly affect the creation of thoughts and behavior in children (12). Studies indicate that the most important cues for action in the field of students' nutrition are mother, teachers, father, TV, friends, books, sister, brother, and magazines (10). The nutrition styles are different in terms of marital status, gender, and social class, furthermore, it should be mentioned that the age, body mass index, and social, cultural and economic capital affect nutrition styles in different ways (13).

Many studies have pointed out the association between low socioeconomic status and malnutrition in adolescents and their parents (14-16). In this regard, the economic status is the most important factor affecting the amount and the type of food. Food intake is strongly associated with income and has a positive relationship with dietary patterns and healthy food choices $(17,18)$. According to the General Population and Housing Census in 2011, Gilan has a morbid situation with uneven development in terms of economic parameters mainly due to 
unemployment. The province was the second unemployed province with an unemployment rate of $16.4 \%$ after Lorestan in 2013 (19).

Positive changes can be made in dietary patterns to reduce the prevalence of obesity and prevent chronic diseases by identifying effective factors in adolescents' nutrition behavior and their modification (20). Considering the increasing trend of adolescents' tendency to junk food and negative consequences of its consumption as well as the lack of detailed evidence of use and the differences in food culture of people in Gilan compared to the rest of Iran (21), present study was conducted with the aim to determine the relationship between consumption of junk food and the personal- familial and social variables among students in their second year of high school and in the school year of 2016-2017.

\section{Methods}

The present study was a cross-sectional descriptive-analytical research conducted during the school year of 2016-2017. The geographic focus of the study consisted of the second year of public high schools (Grades 10, 11 and 12) in educational districts 1 and 2 of Rasht (except for technical and vocational disciplines) including 14 and 8 all-girls and all-boys schools in District 1; and 12 and 11 all-girls and all-boys schools in District 2 (a total of 13654 students). One allgirls and one all-boys school (a total of four schools) were randomly selected from each district. In selection of samples, at first dual educational districts were selected as a sampling class, consequently, all-girls and all-boys schools as sampling clusters, and a school was randomly selected from each cluster per class. Considering 30 students per class, 12 classes (4 classes from each grade) were randomly selected. According to a research by Dehdari et al. (3), the sample size was obtained equal to 113 by equalizing $r$ to -0.30 relating to the correlation coefficient between snack consumption and behavioral intention variables in Table 1, at a 95\% confidence interval and test precision of 0.05 in the following equation.

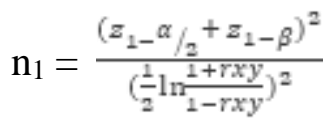

In the present study, each class was considered as a cluster. The sample size was calculated by taking into account the design effect factor of 1.5 as follows:

$224 \times 1.5=336$ 
Finally, 342 samples were studied and solely a male student refused to complete the questionnaire. Therefore, 341 questionnaires were completed and collected. The inclusion criteria were as follows: studying at grade 10 , or 11 or 12 , and the absence of any non-specific disease that influenced samples' diets. Data collection tool of study were questionnaires containing the demographic information, and the researcher-made questionnaire for measuring the consumption of fast food and snacks, derived from Kristen Dunn's standard food frequency inventory with determined validity and reliability by two questions for measuring frequency of junk food consumption with a range of "never" to "more than once a day" and the frequency of junk food consumption by type (drinks, fast food, fried foods, sweet and salty snacks ) ranging from "never" to "more than 4 times a week to every day" in students. In order to determine the reliability, the content validity was evaluated by a panel of ten professors from Shahid Beheshti Faculty of Nursing and Midwifery of Rasht. Since the CVR score (content validity ratio) should be greater than 0.62 for each question, and the CVI (content validity indicator) should be greater than 0.79, a question was deleted because the CVR score was 0.60. The CVR of total questionnaire was 0.97 after removal of this question; and the CVI of total questionnaire was 0.97. The questionnaire was distributed among the studied high schools of Rasht and completed by the self-report method at 20 minutes. The data collection process was carried out during 4 working days from 7th to 14th December, 2016. Data was analyzed by SPSS 21. The frequency distribution was used to describe qualitative variables; and Mann-Whitney and Kruskal-Wallis tests at a significance level of 0.05 were utilized to compare the median frequency of junk food consumption with demographic variables.

\section{Results}

According to the findings, 52.2\% of participants were female, $40.2 \%$ were the first children, $37.5 \%$ were studying in the eleventh grade, and $86.8 \%$ lived with their parents. The majority of them reported the father's job of self-employed (51.6\%) and the mother's job of housewife (78.9\%), in addition they reported both the father's and the mother's education level of high school diploma (48.1\%) and (49.6\%). Totally, 36.1\% reported the family income of 1 to 5.1 million Rials. Based on the findings of Table 1,9.4\% of units ate junk food once or more per day. 
Table 1. Frequency distribution of the students' junk food consumption

\begin{tabular}{|l|c|c|}
\hline Junk food consumption frequency & N & \% \\
\hline Never & 2 & 0.6 \\
\hline Occasionally (Less than once a month) & 77 & 22.6 \\
\hline Once per month & 30 & 8.8 \\
\hline Once per fortnight & 40 & 11.7 \\
\hline Once per week & 66 & 19.4 \\
\hline 2-3 times per week & 74 & 21.7 \\
\hline 4-6 times per week & 20 & 5.9 \\
\hline Once a day & 13 & 3.8 \\
\hline More than once per day & 19 & 5.6 \\
\hline Total & 341 & 100 \\
\hline
\end{tabular}

Table 2 indicates that sweet snacks with $27.3 \%$ were the most abundant kind of junk food.

Table 2. Frequency distribution of the students' junk food consumption during the last week

\begin{tabular}{|c|c|c|c|c|c|c|c|}
\hline Type of junk food & 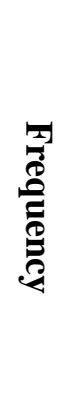 & 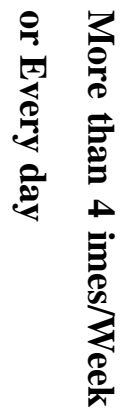 & 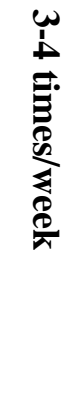 & 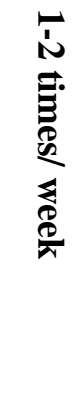 & 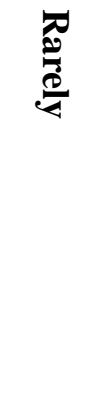 & $\begin{array}{l}Z \\
\substack{9 \\
9} \\
9\end{array}$ & $\frac{\overrightarrow{0}}{20}$ \\
\hline \multirow{2}{*}{$\begin{array}{l}\text { Sweet and carbonated } \\
\text { drinks, Energy drinks, }\end{array}$} & $\mathbf{N}$ & 18 & 21 & 123 & 125 & 54 & 341 \\
\hline & $\%$ & 5.3 & 6.2 & 36.1 & 36.7 & 15.8 & 100 \\
\hline
\end{tabular}




\begin{tabular}{|l|c|c|c|c|c|c|c|}
\hline Fruit flavored drinks & & & & & & & \\
\hline $\begin{array}{l}\text { Fast food meals (e.g. } \\
\text { Hamburgers, Pizza, } \\
\text { Sandwiches, etc. }\end{array}$ & $\mathbf{N}$ & 15 & 64 & 109 & 121 & 32 & 341 \\
\cline { 2 - 9 } & $\mathbf{\%}$ & 4.4 & 18.8 & 32 & 35.5 & 9.4 & 100 \\
\hline \multirow{2}{*}{ Fried foods } & $\mathbf{N}$ & 40 & 117 & 126 & 49 & 9 & 341 \\
\cline { 2 - 9 } & $\mathbf{\%}$ & 11.7 & 34.3 & 37 & 14.4 & 2.6 & 100 \\
\hline \multirow{3}{*}{ Sweet snacks } & $\mathbf{N}$ & 93 & 104 & 74 & 58 & 14 & 341 \\
\cline { 2 - 9 } & $\mathbf{\%}$ & 27.3 & 29.9 & 21.7 & 17 & 4.1 & 100 \\
\hline \multirow{2}{*}{ Salty snacks } & $\mathbf{N}$ & 39 & 72 & 105 & 96 & 29 & 341 \\
\cline { 2 - 9 } & $\mathbf{\%}$ & 11.4 & 21.1 & 30.8 & 28.2 & 8.5 & 100 \\
\hline
\end{tabular}

Table 3 presents that the father's education $(\mathrm{P}-0.037)$ and family income $(\mathrm{P}=0.004)$ had a significant relationship with median frequency of junk food consumption; and the consumption was greater among students with university-educated fathers and family income of more than 2 million Rials.

Table 3. Comparing between students' junk food consumption frequency and demographic characteristics

\begin{tabular}{|c|c|c|c|c|}
\hline \multicolumn{2}{|c|}{ variables } & Mean & SD & $\mathbf{P}$ \\
\hline \multirow{3}{*}{ Grade } & 10th & 4.8 & 2.1 & \multirow{3}{*}{.803} \\
\hline & 11th & 4.6 & 1.9 & \\
\hline & 12th & 4.6 & 2.2 & \\
\hline \multirow{2}{*}{ Gender } & Male & 4.9 & 2 & \multirow{2}{*}{.059} \\
\hline & Female & 4.5 & 2 & \\
\hline \multirow{4}{*}{ Birth Rank } & First child & 4.7 & 2 & \multirow{4}{*}{.110} \\
\hline & Middle child & 4 & 2 & \\
\hline & The Last child & 4.9 & 2 & \\
\hline & Only child & 4.8 & 2.2 & \\
\hline
\end{tabular}




\begin{tabular}{|c|c|c|c|c|}
\hline \multirow{4}{*}{$\begin{array}{l}\text { How to live with } \\
\text { family members }\end{array}$} & Parents & 4.7 & 2.1 & \multirow{4}{*}{.227} \\
\hline & Only Father & 4 & 2.6 & \\
\hline & Only Mather & 3.7 & 1.7 & \\
\hline & Other family members & 4.7 & 2 & \\
\hline \multirow{6}{*}{ Father's job } & Staff & 4.9 & 2.2 & \multirow{6}{*}{.390} \\
\hline & Worker & 4.7 & 2.2 & \\
\hline & Farmer & 3.3 & 2.1 & \\
\hline & Self-employment & 4.6 & 1.9 & \\
\hline & Retired & 4.9 & 1.9 & \\
\hline & Jobless & 4.5 & 2.7 & \\
\hline \multirow{6}{*}{ Mother's job } & Staff & 5.2 & 2.4 & \multirow{6}{*}{.507} \\
\hline & Worker & 3 & 1.4 & \\
\hline & Farmer & 5 & 0 & \\
\hline & Self-employment & 4.9 & 2.1 & \\
\hline & Retired & 5 & 1.8 & \\
\hline & Jobless & 4.6 & 2 & \\
\hline \multirow{4}{*}{ Father's degree } & Illiterate & 4.4 & 1.8 & \multirow{4}{*}{.037} \\
\hline & Under the diploma & 4.4 & 1.9 & \\
\hline & Diploma & 4.6 & 2 & \\
\hline & Graduate & 5.4 & 2.3 & \\
\hline \multirow{4}{*}{ Mother's degree } & Illiterate & 4.2 & 1.9 & \multirow{4}{*}{.158} \\
\hline & Under diploma & 4.6 & 2 & \\
\hline & Diploma & 4.6 & 2 & \\
\hline & Graduate & 5.4 & 2.4 & \\
\hline Monthly income (Rails) & More than 20 & 5.4 & 2.3 & .004 \\
\hline
\end{tabular}




\begin{tabular}{|c|c|c|c|c|}
\hline & 15 to 20 & 5 & 2.1 & \\
\hline & 10 to 15 & 4.5 & 1.9 & \\
\hline & Less than 10 & 4.2 & 1.9 & \\
\hline & Thin & 3.9 & 2 & .096 \\
\hline & Normal weight & 4.7 & 2.1 & \\
\hline & Over weight & 4.9 & 2 & \\
\hline & Fat & 3.7 & 1.6 & \\
\hline & Rarely & 3.6 & 2 & \\
\hline Rate of exposure & From time to time & 4.5 & 1.9 & $<.0001$ \\
\hline & Often & 4.9 & 2 & \\
\hline & Television & 4.2 & 1.8 & \\
\hline & Radio & 0 & 0 & \\
\hline & School & 4.8 & 1.8 & \\
\hline & Newspaper & 2.5 & 0.7 & \\
\hline Type of exposure & Magazine & 3.4 & 1.3 & .143 \\
\hline & $\begin{array}{l}\text { Internet and social } \\
\text { networks }\end{array}$ & 4.8 & 1.9 & \\
\hline & $\begin{array}{l}\text { Outdoor billboards in } \\
\text { public places }\end{array}$ & 4.3 & 1.8 & \\
\hline & Several sources & 4.9 & 2.2 & \\
\hline
\end{tabular}

\section{Discussion}

In the present study, 9.4\% of units reported the frequency of junk food consumption as "once or more per day". Seventy two percent of girls in a study by Ricci, (24), 31.5\% of adolescents in a study by Akman et al. (25), and 33.6\% of units in a study by Akman et al. consumed junk food (26). Different results were due to the different definitions of junk food, different living environment of adolescents, and thus different food styles in different geographic regions, and 
finally different ways of collecting data. Compared to many similar studies, results of the present study indicated the lower consumption of junk food among high school students.

Our results on the use of sweet snacks revealed that 29.9\% consumed "3-4 times per week"; and it was consistent with the findings of a research by Montazerifar et al (35). In the present study, $27.3 \%$ used "more than 4 times per week or every day". Gharib et al. found that $24.2 \%$ of girls and $29.7 \%$ of boys consumed junk food at the same rate (36). High intake of sweet snacks may increase the risk of weight gain and tooth decay in the short term and also the risk of diabetes in adulthood for adolescents in long term. According to our results based on the more consumption of sweet snacks than other junk food, it seems essential to limit the supply of these items and replace them with healthier food in buffets of educational centers.

In our study, there was a statistical significant relationship between father's education level and median frequency of junk food consumption; therefore, the median frequency of junk food consumption was higher among adolescents with university-educated fathers. The studies by Sharifirad et al. (43), Aljilani et al. (18) and Yarmohammadi et al. (44) were in line with the results of present study which confirms significant association between parental education and junk food consumption. On the other hand some studies had inconsistent results with ours; for instance, Ho et al. found that the behaviors such as eating were affected by external factors (such as smell, taste, etc.) in children whose parents had lower education level with a higher frequency of $28 \%$ and $28.3 \%$ than other factors (40). Dehdari et al. reported that the consumption of carbonated drinks significantly decreased in students with educated parents (45). Likewise, Karimi et al., stated that the parental education had a statistical significance relationship with the frequency of healthy snacks consumption by children as the frequency of healthy food increased in children with educated parents (46). However,Some studies such as Ghaffari et al. found no significant difference between parents' education and fast food consumption (8) and also Dehdari et al. reported no difference between the consumption of junk food in students and their parents' education (3). Despite the expectation that the increase in parental education level may create negative attitudes towards the junk food consumption and more aware of the importance of healthy nutrition for adolescents in families, the tendency consume junk food among adolescents increases in such families in today's urban communities, as a result of longer working hours and more involvement of educated parents in outdoor work environments.

In the present study, there was a statistical significant relationship between the families' income 
levels and frequency of junk food consumption, therefore the frequency of junk food consumption was higher among adolescents with family income of greater than 2 million Tomans; and as a result the increased incomes enhanced frequency of junk food consumption. In a study by Aljilani et al., there was a significant relationship between socio-economic status and consumption of fast food consumption; the consumption was greater in children at higher socioeconomic levels (18). Ghaffari et al. noted that there was also a significant association between fast food consumption and family income; accordingly, students with higher economic level used greater amounts of fast food (47). In studies by Kouhi et al. (13), Sharifirad et al. (43), Yarmohammadi et al. (44), and Ghaffari et al. on students, there was a direct relationship between economic status and fast food consumption in adolescents (8). However, the inconsistent results with the present study were also obtained in some studies, for instance, Karimi et al. found that frequency of healthy snacks increased in families with higher income, but there was no significant relationship between family's economic status and dietary behavior in adolescents (40). Dehdari et al. concluded that there was no significant difference between the score of junk food consumption in students and their pocket money (3). Bauer et al. found that adolescents with low socioeconomic status ate more fast food (48). It can be concluded that the favorable economic status acts as a double-edged sword. Although a favorable economic status can lead to the consumption of healthy snacks and proper nutrition for children, it can increase their purchasing power for junk food. It seems that the problem can be solved by the parental supervision and management of children's pocket money for purchasing food items, while maintaining their independence.

In the present study, there was no significant relationship between the median frequency of junk food and education grade, gender, birth order, way of living with family, parents' jobs, and mother's education.

\section{Conclusion}

Despite the fact that high school students were in a better status in terms of junk food consumption than similar studies, the harmful and pathogenic nature of such foods still necessitates the greater attention to the reason for adolescents' tendency towards consumption of junk food. According to the results of our research significant frequency of junk food consumption due to the socio-economic factors, and the higher economic status can have a 
negative impact on the adolescents' nutritional status. Therefore, the amounts of pocket money and its spending way should be controlled in adolescents. Furthermore, the opportunity for more consumption of healthy food and snacks should be provided by managing the hours of parental outdoor presence.

Limitations of the present study included the possibility of errors in recall and willingness to idealism during the self-report. Strengths of the present study included the study of nutritional status in both sexes as well as evaluation of all groups of junk food.

\section{Acknowledgements}

The present paper was part of the master's thesis entitled "The assessment of factors associated with the consumption of junk food based on the theory of planned behavior (TPB) among high school students of Rasht in the school year of 2016-2017", with the registration number of 932413 and the code of ethics (IR.GUMS.REC.1395.257). We are grateful to the esteemed head of Social Determinants of Health (SDH) research center at Gilan University of Medical Sciences, the professors involved in the design and psychometric evaluation of the questionnaire, as well as the principals and the students of high schools in Rasht.

\section{References}

1. Ray D, Ray S, Burman DR, Mondal R, Biswas R, Chakrabarti P, et al. Dyslipidemia is a predictive risk factor for coronary heart diseases (CHD) in young, obese and non-vegeterian junk food eaters, a study conducted in BS medical college, Bankura, West Bengal. JEMDS. 2013; 2(24):4446-54. [DOI:10.14260/jemds/861]

2. Naeem Z. Increasing trend of Junk food use in Saudi Arabia and health implications. Int J Health Sic (Qassim). 2012; 6(1):V-VI. [DOI: 10.12816/0005967]

3. Dehdari T, Chegni M, Dehdari L. Application planned behavior in theory predicting Junk Food consumption among female students. Preventive Care in Nursing \& Midwifery Journal. 2013; 2(2):18-24. [Persian].

4. Vinay Gopal J, Sriram S, Kannabiran K, Seenivasan R. Student's perspective on junk foods: Survey. Sudanese journal of public health. 2012; 7(1):21-5.

5. Naisi N, Aivazi AA, Hoseiny Rad M, Direkvand Moghadam A, Pournajaf A. Knowledge, attitude and performance of K-9 girl students of Ilam city toward puberty health in 2013-14. SJIMU. 2016; 24(1):28-34. [Persian]. [DOI:10.18869/acadpub.sjimu.24.1.28] 
6. Yarmohammadi S, Eftekhar ardebili H, Mahmoodi M, Jazayeri SA, Chamari M. The effect of an educational program based on the BASNEF model on the nutritional behavior of guidance school female pupils. Journal of School of Public Health and Institute of Public Health Research. 2015;13(2):55-68. [Persian].

7. Brownell KD, Schwartz MB, Puhl RM, Henderson KE, Harris JL. The need for bold action to prevent adolescent obesity. Journal of Adolescent Health. 2009; 45(3):S8-S17. [DOI:10.1016/j.jadohealth.2009.03.004]

8. Ghafari M, Ebadi L, Ramzankhani A, Souri H. Fast food consumption and its related factors among students: A cross-sectional study. Health System Research. 2012; 8(6):981-90. [Persian].

9. Purushothaman S, Reddy C, Chaly PE, Priyadarshni I. Predilection for junk food consumption among 15-year-old school children in North Chennai, India. Medical Journal of Islamic World Academy of Sciences. 2015; 23(4):125-30. [DOI: 10.12816/0017517]

10. Alizadeh Siuki H, Jadgal K, Shamaeian Razavi N, Zareban I, Heshmati H, Saghi N. Effects of health education based on health belief model on nutrition behaviors of primary school students in Torbat e Heydariyeh city in 2012. Journal of Health. 2015; 5(4):289-99. [Persian].

11. Doroudi H, Ramazani N. Studing the role of television in strengthening the values of children's and teenagers' literature. Media Studies. 2015; 10(29):37-52. [Persian].

12. Habibi M, HajiSheykhi M, Lavaf H. The relationship between paternal lifestyle and parenting style: The role of father's drug addiction. Iranian Journal of Psychiatry and Clinical Psychology. 2016; 21(4):297-307. [Persian].

13. Kuhi K, Mobarak M, Abdi R. Studying the extent of students' tendency towards Fast foods and effective factors thereupon. Bioethics Journal (Quarterly). 2013; 3(8):157-85. [Persian].

14. Abtahi M, Pouraram H, Djazayeri A, Eshraghian M, Amini M. Relationship between prevalence of overweight and obesity in adolescent girls, and socio-economic status of their families: A case study in Tehran. J Nutri Health. 2016; 2(1):4. [DOI:10.13188/2469$\underline{4185.1000012]}$

15. Ramesh T, Dorosty Motlagh A, Abdollahi M. Prevalence of household food insecurity in the City of Shiraz and its association with socio-economic and demographic factors, 2008. Iranian Journal of Nutrition Sciences \& Food Technology. 2010; 4(4):53-64. [Persian].

16. Najafianzadeh M, Mobarak-Abadi A, Ranjbaran M, Nakhaei M. Relationship between the prevalence of food insecurity and some socioeconomic and demographic factors in the rural households of Arak, 2014. Iranian Journal of Nutrition Sciences \& Food Technology. 2015; 9(4):35-44. [Persian].

17. Pasdar Y, Rezaei M, Darbandi M, Niazi P, Safari Faramani R. Consumption pattern of lipids and the factors affecting their selection among families in Kermanshah (2011). J Kermanshah 
Univ Med Sci. 2014; 18(1):44-52. [Persian].

18. Abdel-Hady D, El-Gilany A, Sarraf B. Dietary habits of adolescent students in Mansoura, Egypt. IJCRIMPH. 2014; 6(6):132-44. [DOI:10.1155/2014/258470]

19. Moradi Masihi V, Talebi M. Spatial analysis about development limitations (Case study: Counties of Guilan Province). Human Geography Research. 2017; 49(1):55-68. [Persian].

20. Hackman CL, Knowlden AP. Theory of reasoned action and theory of planned behaviorbased dietary interventions in adolescents and young adults: a systematic review. Adolesc Health Med Ther. 2014; 5:101-14. [DOI:10.2147/AHMT.S56207]

21. Motamedimehr A, Mesdaghi H. Nutritional geography a modern approach in eastern Guilan tourism. Journal of Geographical Landscape. 2011; 6(15):24-6. [Persian].

22. Hovington J. Junk food denormalization project for young people: junk food marketing survey: 10000 quebec teenagers speak out. Québec en Forme; 2012.

23. Dunn K. Fast-food consumption: application and extension of the theory of planned behaviour to incorporate affective responses and implicit associations. Adelaide South Australia: University of Adelaide; 2008.

24. Ritchie LD. Less frequent eating predicts greater BMI and waist circumference in female adolescents. Am J Clin Nutr. 2012; 95(2):290-6. [DOI:10.3945/ajcn.111.016881]

25. Akman M, Akan H, İzbirak G, Tanrı̈ver Ö, Tilev SM, Yıldız A, et al. Eating patterns of Turkish adolescents: a cross-sectional survey. Nutrition journal. 2010; 9(1):67. [DOI: $\underline{10.1186 / 1475-2891-9-67]}$

26. Jaisheeba AA, Sornaraj R, Gayathri K. Influence of westernized culture and changed dietary habits on the BMI status of the school children of Tirunelveli. Int.J.PharmTech Res. 2012;4(3):1065-77.

27. Karimi H, Shirinkam F, Sajjadi P, Sharifi M, Bayandari M. Dietary pattern, breakfast and snack consumption among middle school students. Holistic Nursing and Midwifery .2015; 25(2):73-83. [Persian].

28. Koivusilta L, Kuoppamäki H, Rimpelä A. Energy drink consumption, health complaints and late bedtime among young adolescents. Int J Public Health. 2016; 61(3):299-306. [DOI: $\underline{10.1007 / \mathrm{s} 00038-016-0797-9]}$

29. Park S, Lee Y, Lee JH. Association between energy drink intake, sleep, stress, and suicidality in Korean adolescents: energy drink use in isolation or in combination with junk food consumption. Nutrition Journal. 2016; 15(1):87. [DOI: 10.1186/s12937-016-0204-7]

30. Oza-Frank R, Zavodny M, Cunningham SA. Beverage displacement between elementary and 64 J Res Dev Nurs Midw, Volume 17, Number 1, January, 2020 
middle school, 2004-2007. J Acad Nutr Diet. 2012; 112(9):1390-6. [DOI:10.1016/j.jand.2012.05.011]

31. Musaiger AO, Kalam F. Dietary habits and lifestyle among adolescents in Damascus, Syria. Ann Agric Environ Med. 2014;21(2):416-9. [DOI:10.5604/1232-1966.1108616]

32. Datar A, Nicosia N. Junk food in schools and childhood obesity. Journal of policy analysis and management. 2012; 31(2):312-37. [DOI:10.1002/pam.21602]

33. Patterson R, Risby A, Chan M-Y. Consumption of takeaway and fast food in a deprived inner London Borough: are they associated with childhood obesity? BMJ Open. 2012; 2(3). [DOI: 10.1136/bmjopen-2011-000402]

34. Singh M, Mishra S. Fast food consumption pattern and obesity among school going (9-13 year) in Lucknow District. IJSR. 2014; 3(6):1672-4.

35. Montazerifar F, Karajibani M, Dashipour AR. Evaluation of dietary intake and food patterns of adolescent girls in Sistan and Baluchistan Province, Iran. Functional Foods in Health and Disease. 2012; 2(3):62-71. [DOI:10.31989/ffhd.v2i3.98]

36. Gharib N, Rasheed P. Energy and macronutrient intake and dietary pattern among school children in Bahrain: a cross-sectional study. Nutrition journal. 2011; 10(1):62. [DOI: 10.1186/1475-2891-10-62]

37. Michels N, Sioen I, Braet C, Eiben G, Hebestreit A, Huybrechts I, et al. Stress, emotional eating behaviour and dietary patterns in children. Appetite. 2012; 59(3):762-9. [DOI:10.1016/j.appet.2012.08.010]

38. Vaida N. Prevalence of fast food intake among urban adolescent students. The International Journal of Engineering and Science. 2013; 2(1):353-59.

39. Mahfouz A, Shatoor A, Khan M, Daffalla A, Mostafa O, Hassanein M. Nutrition, physical activity, and gender risks for adolescent obesity in Southwestern Saudi Arabia. Saudi J Gastroenterol. 2011; 17(5):318-22. [DOI:10.4103/1319-3767.84486]

40. Hou F, Xu S, Zhao Y, Lu Q, Zhang S, Zu P, et al. Effects of emotional symptoms and life stress on eating behaviors among adolescents. Appetite. 2013; 68:63-8. [DOI:10.1016/j.appet.2013.04.010]

41. Branscum P, Sharma M. Comparing the utility of the theory of planned behavior between boys and girls for predicting snack food consumption. Health Promot Pract. 2014; 15(1):134-40. [DOI: 10.1177/1524839913481974]

42. Al-Hazzaa HM, Abahussain NA, Al-Sobayel HI, Qahwaji DM, Musaiger AO. Physical activity, sedentary behaviors and dietary habits among Saudi adolescents relative to age, gender and region. Int J Behav Nutr Phys Act. 2011; 8(1):140. [DOI: 10.1186/1479-5868-8-140] 
43. Sharifirad G, Yarmohammadi P, Azadbakht L, Morowatisharifabad MA, Hassanzadeh A. Determinants of fast food consumption among Iranian high school students based on planned behavior theory. Journal of obesity. 2013:1-7. [DOI:10.1155/2013/147589]

44. Yarmohammadi P, Sharifirad GR, Azadbakht L, Morovati Sharifabad MA, Hassanzadeh A. Predictors of fast food consumption among high school students based on the theory of planned behavior. Journal of Health System Research. 2011; 7(4):449-59. [Persian].

45. Dehdari T, Mergen T. A survey of factors associated with soft drink consumption among secondary school students in Farooj city, 2010. Journal of Jahrom University of Medical Sciences. 2012; 9(4):33-9. [Persian]. [DOI:10.29252/jmj.9.4.33]

46. Karimi- Shahanjarini A, Sharifi M, Bashirian S, Moghimbeigi A. Determinants of Healthy Snacks Choice by Mothers of 1-5 years old children in Hamadan Based on Social Cognitive Theory (SCT). Iranian Journal of Nutrition Sciences \& Food Technology. 2015; 9(4):19-26. [Persian].

47. Ghaffari M, Sherizadeh Y, Rakhshandehroo S, Ramezankhani A. Psychological determinants of fast-food consumption among male students of Khoy city high schools: an application of the theory of planned behavior. Pajoohandeh Journal. 2015; 20(5):266-72. [Persian].

48. Bauer KW, Larson NI, Nelson MC, Story M, Neumark-Sztainer D. Socio-environmental, personal and behavioural predictors of fast-food intake among adolescents. Public Health Nutr. 2009; 12(10):1767-74. [DOI: 10.1017/S1368980008004394]

\section{Bibliographic information of this paper for citing:}

Mirhadyan L, Moradi Latreyi S, Pasha A, et al. Junk food consumption and its associated factors in high school students in Rasht in 2017

J Res Dev Nurs Midw, 2020; 17(1): 52-66.

Copyright @ 2020, Leila Mirhadyan, Saeid Moradi Latreyi, Afsaneh Pasha, Ehsan KazemNejad Leili4. 